\title{
Pulmonary Embolism Mortality Associated with the Necessity of Being Hospitalized Outside the Canton of Residence in Ecuador
}

\author{
David Garrido ${ }^{1 \star}$, Esteban Visarrea ${ }^{2}$, Juan Benalcazar ${ }^{3}$
}

\author{
${ }^{1}$ Hematology Department, Hospital de Clínicas Manuel Quintela, Universidad de la República, URUGUAY \\ ${ }^{2}$ Facultad de Medicina, Universidad Central del Ecuador. Quito, ECUADOR \\ ${ }^{3}$ Hospital de Especialidades de las Fuerzas Armadas N ${ }^{\circ} 1$, Angiology and Vascular Surgery Service, Quito, ECUADOR \\ *Corresponding Author: david_labinmuno@hotmail.com
}

Citation: Garrido D, Visarrea E, Benalcazar J. Pulmonary Embolism Mortality Associated with the Necessity of Being Hospitalized Outside the Canton of Residence in Ecuador. Electron J Gen Med. 2021;18(3):em294. https://doi.org/10.29333/ejgm/10860

\section{ARTICLE INFO}

Received: 25 Dec. 2020

Accepted: 1 Feb. 2021

\section{ABSTRACT}

Introduction: Pulmonary embolism (PE) is a common cause of cardiovascular death, with hospital mortality rates in South America around 14\%. However, there is limited information regarding Ecuador.

Objectives: To present a survival analysis of Ecuadorian patients affected by PE.

Methods: We performed a survival analysis study based on the retrospective review of the hospital discharges by PE in Ecuador from 2011 to 2018 through the Ecuadorian National Statistics and Census Institute databases.

Results: We found 2974 cases of PE. From them, 505 (16.98\%) patients deceased, 59.72\% were females, 64.79\% had an age $\geq 60$ years with an average of 65.04 years, $19.80 \%$ were treated outside their canton of residence, and $7.57 \%$ were associated to acute cor pulmonale (ACP).

Using the Cox regression model, being treated outside the canton of residence (HR $1.40, p<0.05)$ and age $\geq 60$ years (HR 1.64, p<0.05) reduced the overall survival. Contrasting, the absence of ACP improved the OS (HR 0.68, p<0.05).

Excluding patients aged $\geq 60$ years, and with $A C P$, being treated outside the canton of residence increased the risk of death by PE (HR 1.77, $p<0.05)$. However, this effect was non significative in patients $\geq 60$ years of age and with $\operatorname{ACP}(p>0.05)$.

Conclusion: Patients treated by PE outside their canton of residence had an increased risk of mortality during the in-hospital stay, especially those younger than 60 years without ACP.

Keywords: thrombosis, pulmonary embolism, mortality, Ecuador

\section{INTRODUCTION}

Pulmonary embolism (PE) is a disease related to venous thromboembolism (VTE) and is considered one of the most common causes of cardiovascular death after myocardial infarction and stroke [1].

The global average incidence of venous thromboembolism (VTE) is 1-2 cases per 1000 people by year, with an estimated PE incidence ranging from 39 to 115 per 100000 population in Hong Kong and the United States (US), respectively [2,3].

Hospital mortality rates for any ICD-10 (International Classification of Diseases, Tenth Revision) listed PE in the US decreased significantly during the past decade, presenting mortality of $11.4 \%, 7.8 \%, 7.8 \%$, and $7.1 \%$, for the periods 2001 2002, 2003-2004, 2005-2006, and 2007-2008, sequentially [4]. In contrast, in South America, the hospital mortality rate of PE is higher than the reported in developed countries, with $12 \%$ in Argentina, $14.1 \%$ in Brazil, and 14.8\% in Colombia [5-7].

We recently found that most hospitalized Ecuadorian patients with pulmonary embolism died during the first days of the in-hospital stay [8]. This result encompasses the evidence that most patients succumb within the early hours of presentation [9]. Therefore, this study aims to present a survival analysis regarding the impact of the need to be hospitalized outside the canton of residence in patients affected by PE, through the Instituto Nacional de Estadísticas y Censos (Ecuadorian National Statistics and Census Institute, INEC) databases, from 2011 to 2018.

\section{METHODS}

We performed a survival analysis study based on the retrospective review of the hospital discharges by $\mathrm{PE}$ in Ecuador from 2011 to 2018.

Ecuador is a country located to the northwest of South America and borders Colombia to the North, the Pacific Ocean to the West, and Peru to the South and East. The country crosses the Equatorial line and has approximately 17 million inhabitants living in $283560 \mathrm{~km} 2$. It is administrative divided into 24 provinces, with 221 cantons (Figure 1). 
$\mathbf{A}$

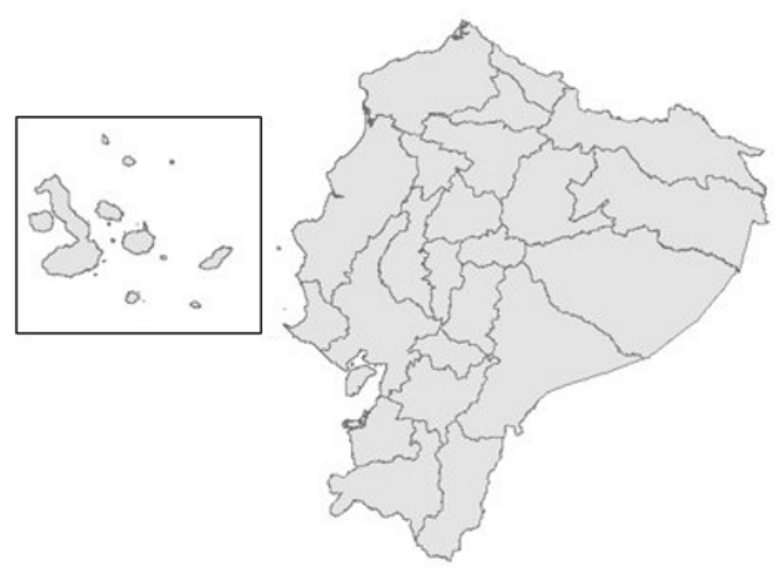

B

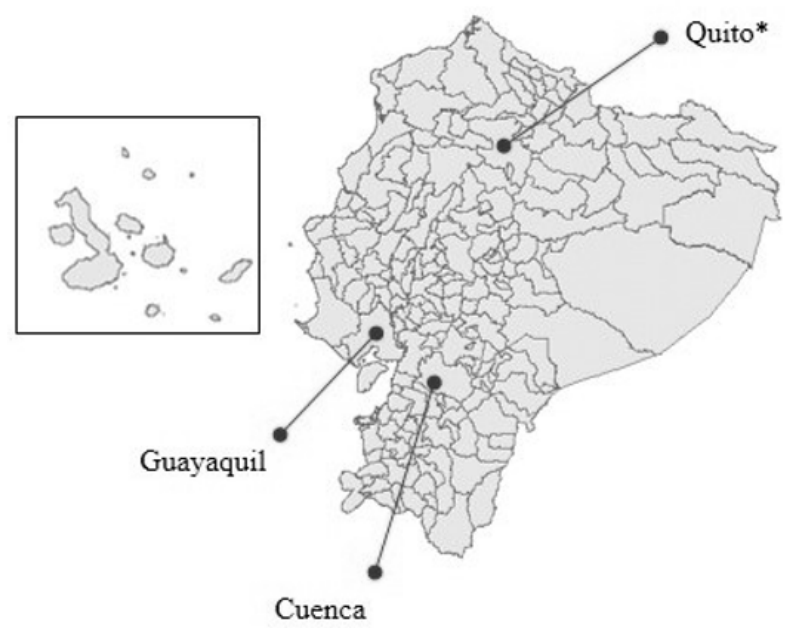

Figure 1. Political and administrative division of Ecuador. A) provinces; B) cantons

\section{Data Obtention}

Data was extracted from governmental databases published each year by INEC. This information is published in SPSS format and is freely available on the web site of the institution.

The datasets analyzed during the current study are available in the (Ecuador en Cifras: Camas y Egresos Hospitalarios) page, (https://www.ecuadorencifras.gob.ec/ camas-y-egresos-hospitalarios/).

As the SPSS document has information about all the hospitalizations reported in the country each year, we used the ICD-10 code 126 to find the patients affected by PE. Additionally, INEC presents a sub-classification of PE in; PE with acute cor pulmonale (ICD-10 126.0) and PE without acute cor pulmonale (ICD-10 I26.9).

For this study, we included the following information; the total number of hospital discharges (HD) distributed by year, the total number of cases with death as the cause of HD each year, diagnosis and sub-classification of acute cor pulmonale, condition at discharge, in-hospital stay days, and demographic characteristics including age, sex, and if the patient was treated in a different canton outside its residence.

\section{Definitions}

To define the hospital mortality rate, we used the equation ((number of patient discharges due to hospital death in a period/number of hospital discharges in the same period) $x$ 100).

In-hospital stay days was defined as the time in which patients remained hospitalized from the admission until discharge.

Acute cor pulmonale refers to a form of acute right heart failure produced by a sudden increase in resistance to blood flow in the pulmonary circulation.

\section{Statistical Analysis}

Statistical analysis was made using SPSS V.25 software and Microsoft Excel 2013. Survival analysis was performed using the Cox regression model along with hazard ratios. With the information provided through this method, we develop a points scoring system to assess in-hospital mortality risk.

\section{RESULTS}

We found 2974 cases of PE. From them, 505 (16.98\%) patients deceased. Regarding the characteristics of the patients, $59.72 \%$ were females, $64.79 \%$ had an age $\geq 60$ years with an average of 65.04 years, $84.97 \% \%$ cases had a hospital length-of-stay $\leq 15$ days, $19.80 \%$ were treated outside their canton of residence, and $7.57 \%$ had a diagnosis of PE with acute cor pulmonale.

Using the multivariate Cox regression model, we found that being treated outside the canton of residence, (HR 1.40, 95\% Cl 1.14 to 1.71 ) and age $\geq 60$ years ( $177 \mathrm{HR} 1.64,95 \% \mathrm{Cl} 1.34$ to 2.01 ) impacted negatively the overall survival during the hospitalization $(p<0.05)$ (Figure $1 A)$. Sex did not influenced OS (HR $1.06,95 \% \mathrm{Cl} 0.89$ to 1.27 ). Not being diagnosed with ACP was associated with an improved OS (HR $0.68,95 \% \mathrm{Cl} 0.52$ to $0.90, \mathrm{p}<0.05)$.

After excluding patients aged $\geq 60$ years, and those with $A C P$, being treated outside the canton of residence increased the risk of death during hospitalization ( $n=983$ ) (HR 1.77, 95\% $\mathrm{Cl} 1.18$ to 2.64, p under 0.05) (Figure 1B). However, this effect was non-significative in those patients with age $\geq 60$ years with ACP (HR 0.91, 95\% Cl 0.42 to 2.00).

In patients treated outside the canton of residence, 296 (50.25\%) were also treated outside the province of residence. In this context, in the group of patients treated outside the province of residence, 157 (52.33\%) were treated in Quito, 36 $(12 \%)$ in Cuenca, and $36(12 \%)$ in Guayaquil.

\section{DISCUSSION}

In this study, being treated outside the canton of residence, along with acute cor pulmonale, and age $\geq 60$ years, were associated with an increased risk of in-hospital mortality by PE in the Ecuadorian population. However, being treated outside the canton of residence had a significative effect especially in patients younger than 60 years of age, and without ACP.

As was reported globally, most patients affected by PE had 60 years of age or more [9]. 
A

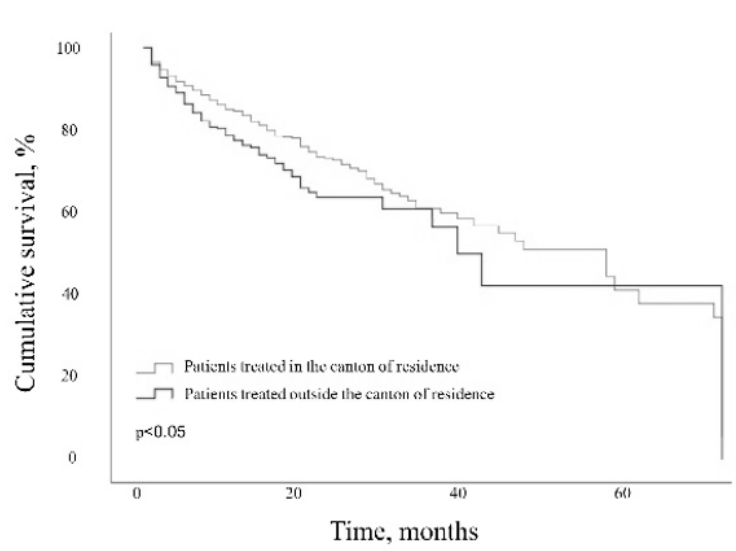

B

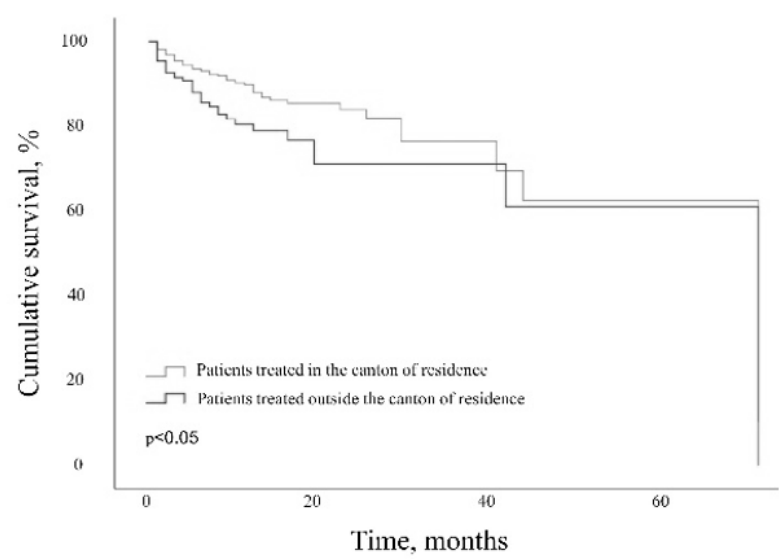

Figure 2. A) Cumulative survival of patients treated outside the canton of residence vs. those treated inside the canton of residence; B) Cumulative survival of patients aged $<60$ years and without acute cor pulmonale treated outside the canton of residence $v$ s. those treated inside the canton of residence.

As established in the Pulmonary Embolism Severity Index (PESI), age is associated with an increased risk of mortality, along with factors that may be related to acute cor pulmonale such as pulse $\geq 110 /$ minute, systolic blood pressure $<100 \mathrm{~mm}$ $\mathrm{Hg}$, and respiratory rate $\geq 30 /$ minute, coinciding with our results [10]. In line with these results, a study in elderly patients diagnosed with VTE, found as independent predictors of overall mortality age (HR 1.32, $95 \% \mathrm{Cl} 1.05-1.65$, per decade), active cancer (HR 5.80, 95\% Cl 4.22-7.97), systolic blood pressure $<100 \mathrm{~mm} \mathrm{Hg}$ (HR 2.77, 95\% Cl 1.56-4.92), diabetes mellitus (HR 1.50, 95\% Cl 1.02-2.22), low physical activity level (HR 1.92, 95\% Cl 1.38-2.66), poly pharmacy (HR, 1.41, 95\% Cl 1.01-1.96), anemia (HR 1.48, 95\% Cl 1.07-2.05), high-sensitivity C-reactive protein $>40 \mathrm{mg} / \mathrm{L}$ (HR 1.88, 95\% Cl 1.36-2.60), ultrasensitive troponin $>14 \mathrm{pg} / \mathrm{mL}(\mathrm{HR} 1.54 ; 95 \% \mathrm{Cl} 1.06-2.25)$, and D-dimer $>3000 \mathrm{ng} / \mathrm{mL}$ (HR 1.45; 95\% Cl 1.04-2.01) [11].

Increased age is a well-described risk factor for suffering VTE, especially the first episode [12]. Also, aging is a condition characterized by multiple comorbidities, which may influence the poor outcomes seen in this group of patients, and is associated with impaired hemostasis mechanisms, increasing both thrombotic and hemorrhagic risk [13].

We found that being treated outside the canton of residence increases the mortality risk. This observation may be related to a delay in the treatment, but we cannot know the precise explanation for this association. However, in favor of this hypothesis, patients with delays in PE diagnosis had a significantly higher probability of unfavorable outcomes (i.e., death, shock, or recurrent venous thromboembolism) at 30 days [14]. Additionally, and linked with high-risk PE, delayed thrombolytic therapy is associated with an increased risk of mortality [15].

\section{Limitations}

Firstly, even when the national registry presented by INEC uses data from public and private institutions in the country, the number of hospital discharges is lower that we can expect. In this context, we believe a significant number of patients are not diagnosed, a situation that concerns us.

As this study is registry-based, the main limitation presented is that we did not have access to clinical and paraclinical information of each patient. These factors do not allow us to analyze how comorbidities influence the overall survival in elderly patients, which is relevant.

Another factor that would be useful to analyze is the type of anticoagulant used, its dose, and the use of thrombolytic therapy in high-risk PE.

Regarding the patients treated outside its canton of residence, it would be interesting to know the time of delay in diagnosis and treatment.

Regarding the definition of acute cor pulmonale, physicians use this code as it is classified in the ICD-10.

In many acute cor pulmonale cases, we believe that there was no echocardiogram evaluation of right ventricle failure. However, there are any published data to confirm this assumption.

To overcome these limitations, we suggest conducting more studies.

\section{Conclusion}

Patients treated by PE outside their canton of residence had an increased risk of mortality during the in-hospital stay, especially those younger than 60 years of age without ACP.

Author contributions: All authors have sufficiently contributed to the study, and agreed with the results and conclusions.

Funding: No funding source is reported for this study.

Declaration of interest: No conflict of interest is declared by authors.

\section{REFERENCES}

1. Barco S, Mahmoudpour SH, Valerio L, Klok FA, Münzel T, Middeldorp $\mathrm{S}$, et al. Trends in mortality related to pulmonary embolism in the European Region, 2000-15: analysis of vital registration data from the WHO Mortality Database. Lancet Respir Med 2020;8(3):277-87. https://doi.org/10.1016/S2213-2600(19)30354-6

2. White RH. The epidemiology of venous thromboembolism. Circulation 2003;107(23 Suppl 1):I4-8. https://doi.org/ 10.1161/01.CIR.0000078468.11849.66 PMid:12814979

3. Wendelboe AM, Raskob GE. Global Burden of Thrombosis: Epidemiologic Aspects. Circ Res 2016;118(9):1340-7. https://doi.org/10.1161/CIRCRESAHA.115.306841 PMid:27126645 
4. Tsai J, Grosse SD, Grant AM, Hooper WC, Atrash HK. Trends in in-hospital deaths among hospitalizations with pulmonary embolism. Arch Intern Med 2012;172(12):960-1. https://doi.org/10.1001/archinternmed.2012.198 PMid:22473671

5. Cigalini I, Igolnikof D, Scatularo C, Jauregui J, Bernal M, García SZ, et al. Acute Pulmonary Embolism in Argentina. XX CONAREC Registry. Rev Argent Cardiol. 2019;87(2):1316. https://doi.org/10.7775/rac.87.2.14603

6. Ceresetto JM. Venous thromboembolism in Latin America: a review and guide to diagnosis and treatment for primary care. Clinics 2016;71(1):36-46. https://doi.org/10.6061/ clinics/2016(01)07

7. Dennis RJ, Rojas MX, Molina A, Roa J, Granados M, Londoño $A$, et al. Clinical course and survival in pulmonary embolism: Results of the Colombian multicentric registry (EMEPCO). Acta Med Colomb. 2008;33(3):111-6.

8. Garrido D, Visarrea E. Comment on the published paper entitled Predictors of Early Death in Patients with Acute Pulmonary Embolism by Akgüllü Ç et al. Am J Emerg Med. 2020 Jun 10:S0735-6757(20)30497-6. https://doi.org/ 10.1016/j.ajem.2020.06.015 PMID:32601005

9. Bĕlohlávek J, Dytrych V, Linhart A. Pulmonary embolism, part I: Epidemiology, risk factors and risk stratification, pathophysiology, clinical presentation, diagnosis and nonthrombotic pulmonary embolism. Exp Clin Cardiol. 2013;18(2):129-38.

10. Aujesky D, Obrosky DS, Stone RA, et al. Derivation and validation of a prognostic model for pulmonary embolism. Am J Respir Crit Care Med 2005;172:1041-6. https://doi.org/10.1164/rccm.200506-8620C PMid:16020800 PMCid:PMC2718410
11. Faller N, Limacher A, Méan M, Righini M, Aschwanden M, et al. Predictors and Causes of Long-Term Mortality in Elderly Patients with Acute Venous Thromboembolism: A Prospective Cohort Study. Am J Med. 2017 Feb;130(2):198206. https://doi.org/10.1016/j.amjmed.2016.09.008

12. Engbers MJ, van Hylckama Vlieg A, Rosendaal FR. Venous thrombosis in the elderly: incidence, risk factors and risk groups. J Thromb Haemost. 2010 Oct;8(10):2105-12. https://doi.org/10.1111/j.1538-7836.2010.03986.x PMID:20629943

13. Ochi A, Adachi T, Inokuchi K, Ogawa K, Nakamura Y, Chiba $Y$, et al. Effects of Aging on the Coagulation Fibrinolytic System in Outpatients of the Cardiovascular Department. Circ J. 2016;80(10):2133-40. https://doi.org/10.1253/ circj.CJ-16-0530 PMid:27568850

14. Goyard C, Côté B, Looten V, Roche A, Pastré J, Marey J, et al. Determinants and prognostic implication of diagnostic delay in patients with a first episode of pulmonary embolism. Thromb Res. 2018;171:190-8. https://doi.org/ 10.1016/j.thromres.2018.08.015 PMid:30190113

15. Beydilli I, Yılmaz F, Sönmez BM, Kozacı N, Yılmaz A, Toksul $\mathrm{IH}$, et al. Thrombolytic therapy delay is independent predictor of mortality in acute pulmonary embolism at emergency service. Kaohsiung J Med Sci. 2016;32(11):5728. https://doi.org/10.1016/j.kjms.2016.09.004 PMid: 27847100 